\title{
ANÁLISE DE EXTREMOS DE TEMPERATURA MÁXIMA DO AR NA REGIÃO OESTE DA BAHIA
}

\author{
Silvia Oliveira Dayube ${ }^{1}$ \\ Mariana Lima de Jesus ${ }^{2}$ \\ Luis Moreira de Araújo Junior ${ }^{3}$ \\ Marcos Antônio Vanderlei Silva ${ }^{4}$
}

Resumo: Extremos climáticos consistem em eventos cuja variável contenha valores com grande desvio em relação a sua tendência estatística, os quais são peculiares para cada região e apresentam potencial para influenciar nas atividades agropecuárias locais. Logo, objetivou-se descrever e analisar a tendência da variabilidade dos extremos elevados de temperatura do ar obtidos na estação convencional da cidade de Barreiras, Bahia. A análise foi realizada utilizando dados de temperatura máxima do ar registrados em frequência diária do ano de 1995 ao ano de 2014, disponibilizados pelo Instituto Nacional de Meteorologia (INMET). Os valores extremos elevados foram definidos como sendo aqueles superiores ao nono decil. Os valores do nono decil apresentaram média de $37,46^{\circ} \mathrm{C}$. Observou-se que houve uma tendência de diminuição da frequência em que ocorrem extremos de temperatura elevada.

Palavras-chave: Análise de regressão; Temperatura instantânea; Estimador.

\footnotetext{
1 Engenheira Agrônoma/Universidade do Estado da Bahia, Brasil. E-mail: sildayube@hotmail.com.

2 Mestre/Universidade Federal do Espírito Santo, Brasil. E-mail: marianaldejesus@gmail.com.

3 Doutorando/Universidade Federal do Espírito Santo, Brasil. E-mail: luisjrmoreira@gmail.com.

${ }^{4}$ Professor/Universidade do Estado da Bahia, Brasil. E-mail: maavsilva@uneb.br.
} 